$$
\begin{gathered}
\text { 대구지역 치과환자들의 치과 의료기관 선택기준 } \\
\text { 이현주 }{ }^{1} \text {, 황태윤 }{ }^{2 \ddagger}, \text { 박사라 }^{3} \\
{ }^{1} \text { 대구보건대학 치위생과, }{ }^{2} \text { 영남의대 예방의학교실, } \\
{ }^{3} \text { 영남대학교 대학원 보건학과 박사과정 }
\end{gathered}
$$

\title{
Factors for Choice on Dental Care Facilities among Dental Patients in Dageu
}

\author{
Hyun-Ju Lee ${ }^{1}$, Tae-Yoon Hwang ${ }^{2} \ddagger$, Sa-Ra Park ${ }^{3}$ \\ ${ }^{1}$ Department of Dental Hygiene, Daegu Health College, \\ 2Department of Preventive Medicine and Public Health, College of Medicine, Yeungnam University, \\ ${ }^{3}$ Doctorate Course, Department of Public Health, Graduate School, Yeungnam University
}

\begin{abstract}
$<$ Abstract $>$
The purpose of this study is to identify if dental patients discriminate between dental clinic and dental hospital and the related factors for choice of dental facilities.

A self-administered questionnaire survey was conducted from March 21 to April 11, 2011. Among 430 dental patients who visited dental clinic or dental hospital twice or more in Daegu, 410 dental patients were included in analysis.

A total of $73.6 \%$ of the dental clinic visitors recognized correctly that the visiting facility was dental clinic and $82.3 \%$ of dental hospital visitors did correctly. Therefore, it can be said that dental hospital visitors recognize better the type of dental care facilities they visit.

When it comes to choosing the dental facility, there were not much differences between the clinic and hospital patients in this study. Human resources, facilities and equipment, service are factors for choosing dental clinic and dental hospital in order. However, modern dental facility and equipment were more important factor for patients to choose dental hospital than clinic.

It will be necessary for dental clinic or dental hospital to develop its own specific service to fulfill dental patients' needs through further studies on factors for choosing dental facilities.
\end{abstract}

Key Words : Dental Patients, Facilities, Factors

‡Corresponding author(luke@ynu.ac.kr) 


\section{I . 서론}

오늘날 의료계에는 의료기술의 발전, 국민들의 건강에 대한 관심 증가, 생활수준의 향상으로 의료 에 대한 높은 기대와 고급화 경향이 나타나고 있 다. 또 의학 지식의 대중화와 권리 의식의 향상에 따라 의료이용자들의 역할도 능동적으로 변화하고 있다.

한편, 의료기관 및 의료 인력의 수적, 양적 증가 와 기존 의료기관의 확장에 따른 의료공급의 증대 는 의료기관간 경쟁을 심화시켰으며, 특히 치과 의 료서비스에서는 개원 치과병·의원의 증가, 체인화 경향 등으로 경쟁은 날로 심화되고 있다. 또 치과 질환 자체가 치명률이 낮으며 만성적인 병의 진행 을 가짐과 동시에 경제적으로 가격 탄력성이 큰 특성이 있기 때문에 그 어려움은 더욱 큰 실정이 다.

치과병원은 치과의사가 의료를 행하는 곳으로서 입원 시설의 제한을 받지 않는 곳이며, 치과의원은 치과의사가 의료를 행하는 곳으로서 진료에 지장 이 없는 시설을 갖춘 의료기관을 말한다. 이와 같 이 치과병원과 치과의원은 크게 명확히 구분이 되 지 않는 종별이지만 현재의 의료기관 대형화 추세 로 치과병원이 증가하고 있고, 또 해마다 많은 치 과의사의 배출로 치과의원 또한 증가하고 있는 추 세이다.

1990년 이후 2009 까지 치과병·의원의 연평균 증가율은 $5.1 \%$ 로, 2001 년 치과병원 60 개소와 치과 의원 10,556 개소에서 2010 년 188 개소와 14,074 개 소로 10 년 사이 치과병원은 3배, 치과의원 약 $33 \%$ 이상 증가하였으며, 2010년 기준 면허 치과의사는 25,379명이었다[1]. 하지만 국민건강보험공단에 따 르면, 하루에 14 곳 이상의 의료기관들이 폐업할 정 도로 의료기관의 경영난은 심각한데 실제로 2011 년에 폐업한 치과병원은 20 개소, 치과의원은 730 개 소로 조사되었다[2].
의료기관을 둘러싼 급변하는 의료 환경 속에서 의료기관이 경쟁우위를 확보하기 위해서는 의료소 비자의 옥구를 파악하고 의료소비자가 원하는 양 질의 서비스를 제공하는 소비자 중심의 차별화된 의료서비스를 제공할 수 있어야 한다[3]. 치과 의 료기관의 경우에도 종별에 따라 내원하는 치과 환 자들에게 차별화된 서비스를 제공하기 위해서는 치과환자들의 치과 의료서비스에 대한 옥구를 파 악하고 치과 의료기관을 선택하는 기준을 파악하 는 것이 필요 할 것이다.

이와 관련된 국내 연구들로는 치과의원 선택기 준[4][5], 치과 의료기관을 선택하는 요인에 관한 조사연구[6][7], 의료소비자의 라이프스타일에 의한 치과진료기관 선택에 관한 연구[8], 치과 의료기 관 선택요인이 만족과 재이용 의도에 미치는 영향 [9], 지역사회주민의 치과 의료기관 선택에 관한 연구[10] 등이 있지만, 치과의원과 치과병원의 내 원환자를 구분하여 선택기준을 연구한 결과는 미 흡한 실정이다.

따라서 이 연구는 치과환자들의 치과의원과 치 과병원의 종별 인지 여부와 치과의원 및 치과병원 을 선택하는 요인들을 구분하여 파악함으로써 치 과 의료기관들이 소비자 욕구에 부합하는데 필요 한 기초정보를 제공하고자 실시하였다.

\section{I. 연구방법}

2011년 3월 21일부터 4월 11일까지 원장의 연구 협조 동의를 얻은 대구광역시 소재 10 개 치과 의 료기관을 방문한 환자 중 만 19세 이상 재진환자 를 대상으로 연구의 목적을 설명하고 연구 참여 동의를 구한 후 구조화된 자기기입식 설문지로 총 430 명에 대해 설문조사를 하였으며, 응답이 불성실 한 자료를 제외한 410 명(치과의원 190 명, 치과병원 220명)을 최종 분석 대상으로 하였다.

설문지는 일반적 특성, 치과 의료기관 종별 인 
지도, 내원한 치과 의료기관 선택 기준 중요도로 구성하였다.

치과 의료기관 선택기준 도구는 $\mathrm{Khang}[4]$ 이 작 성한 소비자의 치과의원 선택기준에 관한 연구의 측정도구와 선행연구를 토대로 이 연구에 맞게 수 정 및 보완하여 사용하였다.

내원한 치과 의료기관 선택 기준 항목들은 인력 부문으로 치과의사의 실력, 치과의사의 명성, 치과 의사의 친절도, 치과직원의 친절도로 구성하였고, 시설 및 장비 부문으로 현대적인 의료시설, 치과 의료기관의 규모, 치과 의료기관의 실내 환경 및 분위기, 주차시설의 편리성으로 구성하였으며, 서 비스 부문으로 진료대기 시간, 야간치료 가능 여 부, 저렴한 치료비용, 대중교통의 편리성, 치과 의 료기관 종사자와의 친분으로 구성하였다.

내원한 치과 의료기관의 선택 기준 중요도는 각 항목별로 매우 중요하였다 3점, 중요하였다 2점,
중요하지 않았다 1점, 전혀 중요하지 않았다 0점 등 3점 만점으로 구성하였다.

수집된 자료는 엑셀 프로그램을 이용하여 각 항 목별 측정결과를 정리하고 코딩한 후 SPSS version 18.0 통계프로그램을 이용하여 빈도분석, t-검정, 비율검정, 교차분석을 실시하였다.

III. 결과

연구 대상자의 성별은 남자 159 명 $(38.8 \%)$, 여자 251 명 $(61.2 \%)$ 이었고, 연령은 29세 이하 123명 (30.0\%), 30-39세 122명(29.8\%), 40-49세 69명 $(16.8 \%), 50$ 세 이상 96 명 $(23.4 \%)$ 이었다. 교육정도는 중졸 이하 22명( $5.4 \%)$, 고졸 108 명 $(26.3 \%)$, 대졸 이상 280 명(68.3\%)이었다. 월수입은 199만 원 이하 148 명(36.1\%), 200-399만 원 173명(42.2\%), 400만 원 이상 89 명 $(21.7 \%)$ 이었다<Table $1>$.

$<$ Table 1> Sociodemographic characteristics of the study subjects

Unit: No. $(\%)$

\begin{tabular}{|c|c|c|c|c|c|}
\hline Characteristics & Subjects & Dental clinic & Dental & hospital & P-value \\
\hline \multicolumn{6}{|l|}{ Gender } \\
\hline Male & $159(38.8)$ & $76(40.0)$ & & $83(37.7)$ & \multirow{2}{*}{0.638} \\
\hline Female & $251(61.2)$ & $114(60.0)$ & & 137(62.3) & \\
\hline \multicolumn{6}{|l|}{ Age } \\
\hline$\leq 29$ & 123(30.0) & $51(26.8)$ & & $72(32.7)$ & \multirow{4}{*}{0.609} \\
\hline $30-39$ & $122(29.8)$ & $58(30.5)$ & & $64(29.1)$ & \\
\hline $40-49$ & $69(16.8)$ & $33(17.4)$ & & $36(16.4)$ & \\
\hline $50 \leq$ & $96(23.4)$ & $48(25.3)$ & & $48(21.8)$ & \\
\hline \multicolumn{6}{|l|}{ Educational Status } \\
\hline$\leq$ Junior high school & $22(5.4)$ & $10(5.3)$ & & $12(5.5)$ & \multirow{3}{*}{0.006} \\
\hline High school & 108(26.3) & $36(18.9)$ & & $72(32.7)$ & \\
\hline$\leq$ College & $280(68.3)$ & $144(75.8)$ & & $136(61.8)$ & \\
\hline \multicolumn{6}{|l|}{ Monthly Income(10,000 Won) } \\
\hline$\leq 199$ & 148(36.1) & 63(33.2) & & $85(38.6)$ & \multirow{3}{*}{0.209} \\
\hline 200-399 & $173(42.2)$ & $89(46.8)$ & & $84(38.2)$ & \\
\hline $400 \leq$ & $89(21.7)$ & $38(20.0)$ & & $81(23.2)$ & \\
\hline Subjects & $410(100.0)$ & 190(100.0) & & $220(100.0)$ & \\
\hline
\end{tabular}


내원 치과 의료기관 종별 인지 여부에서 내원 당시 치과 의료기관 종별을 인지하고 내원하였다 고 응답한 대상자는 410 명 중 282 명 $(68.8 \%)$ 이었고 <Table 2>, 응답한 282명 중 치과의원임을 정확히 인지하고 치과의원에 내원한 환자는 125 명 중 92 명 $(73.6 \%)$, 치과병원임을 정확히 인지하고 치과병 원에 내원한 환자는 157 명 중 130 명 $(82.8 \%)$ 이었다 $(\mathrm{p}<0.01)<$ Table $3>$.

성별, 연령별, 교육 정도에 따른 치과 의료기관 종별 인지 정확도는 통계학적으로 유의한 차이는 없었지만, 치과의원 내원 환자 중 월수입이 199만 원 이하 32 명 $(88.9 \%), 400$ 만 원 이상 26 명 $(83.9 \%)$, 200-399만원 34명(58.6\%)순으로 치과 의료기관 종 별을 정확하게 인지하였다 $(\mathrm{p}<0.01)<$ Table $4>$.

전체 연구 대상자의 치과 의료기관 선택 기준은
치과의원, 치과병원 모두 의료인력, 의료서비스, 의 료시설 및 장비의 순이었고, 치과의원과 치과병원 의 선택기준에 있어 시설 및 설비 부문 점수는 치 과의원 $1.92 \pm 0.50$, 치과병원 $2.04 \pm 0.44$ 점으로 통계 적으로 유의한 차이가 있었다 $(\mathrm{p}<0.01)$. 개별 항목 중 실내 환경 및 분위기, 저렴한 치료비용, 대중교 통의 편리성 등이 치과병원이 치과의원에 비하여 통계적으로 유의하게 점수가 높았다 $(\mathrm{p}<0.01)$. 치과 의원의 선택기준 점수는 치과의사의 실력 2.74점, 치과의사의 명성과 치과직원의 친절도 2.46점, 진 료대기 시간 2.27점, 현대적인 의료시설 2.20점 순 으로 높았고, 치과병원의 선택기준 점수는 치과의 사의 실력 2.75점, 치과직원의 친절도 2.42점, 치과 의사의 명성 2.41점, 현대적인 의료시설 2.30점, 대 중교통의 편리성 2.21점으로 조사되었다<Table 5>.

$<$ Table 2> Recognition status on type of dental care facilities at the time of visiting

Unit: No.(\%)

\begin{tabular}{|c|c|c|c|c|c|}
\hline Items & & Subjects & Dental clinic & Dental hospital & P-value \\
\hline \multicolumn{6}{|c|}{ Recognition of type of dental care facilities } \\
\hline & Yes & 282(68.8) & $125(65.8)$ & 157(71.4) & \multirow{2}{*}{0.225} \\
\hline & No & 128(31.2) & $65(34.2)$ & $63(28.6)$ & \\
\hline Total & & $410(100.0)$ & 190(100.0) & $220(100.0)$ & \\
\hline
\end{tabular}

$<$ Table $3>$ Comparison of recognition accuracy rate of type of dental care facilities

Unit: No. (\%)

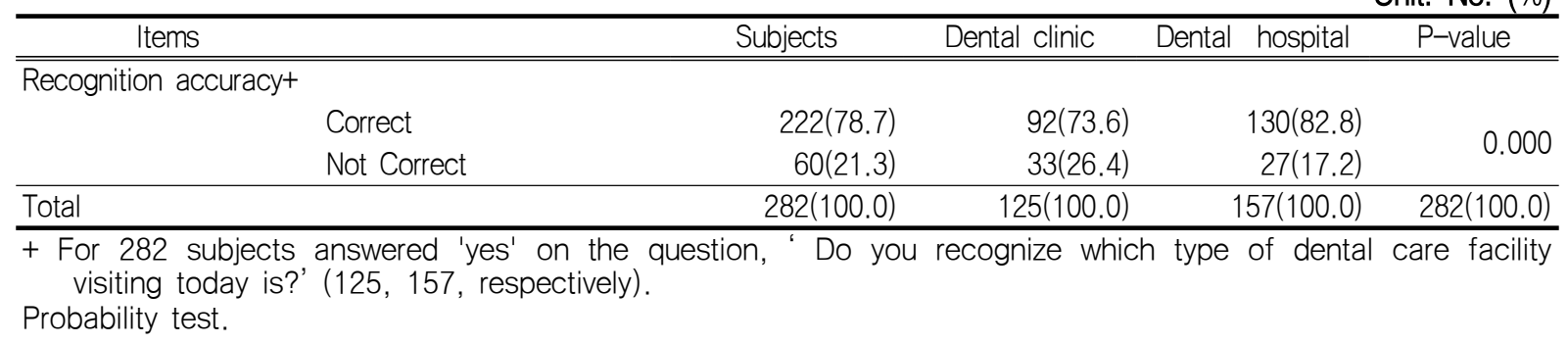


$<$ Table $4>$ Recognition accuracy of type of dental care facilities by sociodemographic characteristics

Unit: No. (\%)

\begin{tabular}{|c|c|c|c|c|c|c|}
\hline \multirow{3}{*}{ Sociodemographic characteristics } & \multicolumn{6}{|c|}{ Recognition accuracy } \\
\hline & \multicolumn{3}{|c|}{ Dental clinic } & \multicolumn{3}{|c|}{ Dental hospital } \\
\hline & Subjects & Correct & P-value & Subjects & Correct & P-value \\
\hline \multicolumn{7}{|l|}{ Gender } \\
\hline Male & 55 & $37(67.3)$ & 0.155 & 59 & $52(88.1)$ & 0.169 \\
\hline Female & 70 & $55(78.6)$ & & 98 & $78(79.6)$ & \\
\hline \multicolumn{7}{|l|}{ Age } \\
\hline$\leq 29$ & 27 & $18(66.7)$ & 0.521 & 48 & $39(81.3)$ & 0.073 \\
\hline 30-39 & 36 & $25(69.4)$ & & 50 & $39(78.0)$ & \\
\hline $40-49$ & 24 & 18(75.0) & & 24 & $18(75.0)$ & \\
\hline $50 \leq$ & 38 & $31(81.6)$ & & 35 & $34(97.1)$ & \\
\hline \multicolumn{7}{|l|}{ Educational Status } \\
\hline$\leq$ Junior high school & 5 & $4(80.0)$ & 0.927 & 9 & $8(88.9)$ & 0.343 \\
\hline High school & 24 & $18(75.0)$ & & 45 & $40(88.9)$ & \\
\hline$\leq$ College & 96 & 70(72.9) & & 103 & $82(79.6)$ & \\
\hline \multicolumn{7}{|l|}{ Monthly Income(10,000 Won) } \\
\hline$\leq 199$ & 36 & $32(88.9)$ & 0.002 & 57 & $50(87.7)$ & 0.261 \\
\hline 200-399 & 58 & $34(58.6)$ & & 60 & $46(76.7)$ & \\
\hline $400 \leq$ & 31 & $26(83.9)$ & & 40 & $34(85.0)$ & \\
\hline Total & 125 & $92(73.6)$ & & 157 & 130(82.8) & \\
\hline
\end{tabular}

$<$ Table $5>$ Scores according to choosing criteria for dental care facilities

\begin{tabular}{|c|c|c|c|c|}
\hline Items & $\begin{array}{l}\text { Subjects } \\
(n=410)\end{array}$ & $\begin{array}{c}\text { Dental clinic } \\
\quad(n=190)\end{array}$ & $\begin{array}{c}\text { Dental hospital } \\
(n=220)\end{array}$ & P-value \\
\hline \multicolumn{5}{|l|}{$\overline{\text { Human Resources }}$} \\
\hline Skill of dentist & 2.75 & 2.74 & 2.75 & 0.860 \\
\hline Reputation of dentist & 2.43 & 2.46 & 2.41 & 0.361 \\
\hline Kindness of dentist & 1.97 & 1.92 & 2.02 & 0.110 \\
\hline Kindness of health workers & 2.44 & 2.46 & 2.42 & 0.454 \\
\hline Mean $\pm S D$ & $2.40 \pm 0.39$ & $2.39 \pm 0.41$ & $2.40 \pm 0.38$ & 0.865 \\
\hline \multicolumn{5}{|l|}{ Facilities and Equipment } \\
\hline Modern of facility and equipment & 2.26 & 2.20 & 2.30 & 0.106 \\
\hline Scale of facility & 1.83 & 1.80 & 1.85 & 0.432 \\
\hline Interior environment and atmosphere & 1.74 & 1.61 & 1.86 & 0.000 \\
\hline Convenience for parking & 2.10 & 2.07 & 2.13 & 0.307 \\
\hline Mean \pm SD & $1.98 \pm 0.47$ & $1.92 \pm 0.50$ & $2.04 \pm 0.44$ & 0.013 \\
\hline \multicolumn{5}{|l|}{ Service } \\
\hline Waiting time & 2.23 & 2.27 & 2.20 & 0.219 \\
\hline Availability of treatment at night & 2.16 & 2.15 & 2.16 & 0.816 \\
\hline Low service price & 1.87 & 1.74 & 1.99 & 0.002 \\
\hline Convenience of transportation & 2.09 & 1.94 & 2.21 & 0.000 \\
\hline Being familiar to health worker & 1.49 & 1.47 & 1.50 & 0.694 \\
\hline Mean $\pm S D$ & $1.94 \pm 0.51$ & $1.91 \pm 0.51$ & $1.96 \pm 0.52$ & 0.283 \\
\hline
\end{tabular}

Values are mean score (a three-point scale).

T-test. 
치과 의료기관 종별을 정확하게 인지한 환자들 의 선택 기준도 전체 연구 대상자의 선택 기준과 동일하게 치과의원, 치과병원 모두 의료인력, 의료 서비스, 의료시설 및 장비의 순이었고, 치과병원의 시설 및 장비의 점수가 또한 유의하게 높았다 $(p<0.01)$. 개별 항목 중에는 실내 환경 및 분위기, 대중교통의 편리성 등이 치과병원이 치과의원에 비하여 통계적으로 유의하게 점수가 높았다 $(\mathrm{p}<0.01)$. 치과의원의 선택기준 점수는 치과의사의 실력 2.84점, 치과직원의 친절도 2.51점, 치과의사 의 명성 2.49점, 진료대기 시간 2.35점, 현대적인 의료시설 2.24점 순으로 높았고, 치과병원의 선택 기준 점수는 치과의사의 실력 2.80 점, 치과직원의 친절도 2.45점, 치과의사의 명성 2.41점, 현대적인 의료시설 2.38점, 진료대기 시간 2.24점으로 조사되 었다<Table 6>.

\section{$<$ Table $6>$ Comparison of scores according to choosing criteria for dental care facilities}

\begin{tabular}{|c|c|c|c|c|}
\hline Items & $\begin{array}{l}\text { Subjects } \\
(\mathrm{N}=222)\end{array}$ & $\begin{array}{l}\text { Dental clinic } \\
\qquad(n=92)\end{array}$ & $\begin{array}{l}\text { Dental hospital } \\
\qquad(n=130)\end{array}$ & P-value \\
\hline \multicolumn{5}{|l|}{ Human Resources } \\
\hline Skill of dentist & 2.82 & 2.84 & 2.80 & 0.511 \\
\hline Reputation of dentist & 2.44 & 2.49 & 2.41 & 0.270 \\
\hline Kindness of dentist & 2.08 & 2.04 & 2.10 & 0.530 \\
\hline Kindness of health workers & 2.47 & 2.51 & 2.45 & 0.368 \\
\hline Mean \pm SD & $2.45 \pm 0.37$ & $2.47 \pm 0.39$ & $2.44 \pm 0.36$ & 0.533 \\
\hline \multicolumn{5}{|l|}{ Facilities and Equipment } \\
\hline Modern of facility and equipment & 2.32 & 2.24 & 2.38 & 0.106 \\
\hline Scale of facility & 1.93 & 1.86 & 1.98 & 0.200 \\
\hline Interior environment and atmosphere & 1.86 & 1.68 & 1.98 & 0.002 \\
\hline Convenience for parking & 2.12 & 2.09 & 2.14 & 0.528 \\
\hline Mean $\pm S D *$ & $2.06 \pm 0.46$ & $1.97 \pm 0.51$ & $2.12 \pm 0.42$ & 0.017 \\
\hline \multicolumn{5}{|l|}{ Service } \\
\hline Waiting time & 2.28 & 2.35 & 2.24 & 0.180 \\
\hline Availability of treatment at night & 2.16 & 2.18 & 2.14 & 0.639 \\
\hline Low service price & 1.91 & 1.79 & 2.00 & 0.067 \\
\hline Convenience of transportation & 2.07 & 1.92 & 2.17 & 0.008 \\
\hline Being familiar to health worker & 1.51 & 1.45 & 1.55 & 0.322 \\
\hline Mean $\pm S D$ & $1.97 \pm 0.54$ & $1.94 \pm 0.53$ & $1.98 \pm 0.55$ & 0.591 \\
\hline
\end{tabular}

For whom recognized type of dental care facilities correctly.

Values are mean score (a three-point scale).

T-test. 


\section{IV. 결론 및 제언}

의료기관의 경쟁심화와 의료 소비자 중심의 시 장에서 의료이용자들의 다양한 욕구와 선택요인 등을 파악하여 차별화된 서비스를 제공하는 것은 중요한 일이다.

이 연구는 치과환자들의 치과 의료기관 별 선택 기준을 파악하여 치과 의료소비자들의 욕구를 파 악하고 그에 따른 대응 방안을 모색하는데 도움을 주고자 하였다.

치과 의료기관 종별 인지 여부에 따른 종별 인 지 정확도에서 치과병원은 $82.8 \%$, 치과의원 은 $73.6 \%$ 로 환자들은 치과병원을 더 많이 정확하게 인지하고 방문하는 것으로 나타났다. 이는 치과병 원이 치과의원보다 규모가 크고 접근성이 좋은 위 치에 입지하고 있으며 적극적인 홍보의 결과로 치 과의원보다 치과병원을 정확하게 인지하는 환자가 많은 것으로 추정할 수 있다.

치과 의료기관 내원환자의 치과 의료기관 종별 인지상태에 따른 선택기준 점수 비교에서는 치과 의원과 치과병원 모두 인력부분의 평균점수가 각

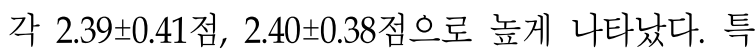
히, 인력부분에서 치과의사의 실력이 2.75점으로 가장 높게 나타났고, 다음으로 인력부분의 치과직 원의 친절도 2.44 점, 치과의사의 명성 2.43 점, 시설 및 장비부분에서 현대적인 의료시설 2.26점, 서비 스 부분의 진료대기 시간 2.23점 순이었다. 이는 치과 의료기관 선택 요인으로 치과의사의 의학적 수준이 5점 만점에 4.83점[5], 76.2\%[11], 41.3\%[12] 가 의료진의 기술과 전문성을 1 순위로 가장 중요 시 된다는 연구들과 일치하는 결과였고, 또 환자가 의료기관을 선택하는데 의사의 실력과 의술에 신 뢰감[13][14]이 중요하다는 결과와 일치한다. 또한 환자의 의료기관 선택요인으로 의원은 직원들의 태도, 병원은 교통의 편리성이 중요하고[15], 의료 진의 친절한 서비스가 중요하며[16], 치과의원 선
택 요인으로 진료대기 시간이, 치과병원 선택요인 으로 교통의 편리성이 선택요인이라는[17] 연구와 도 유사한 결과이다. 하지만 병원선택요인이 시설 과 환경요인이 가장 높게 나온 Lee와 Sohn[18]의 연구와는 다소 상이한 결과이다.

이들 결과는 치과 의료기관에 대한 요구가 예전 의 의료행위자체의 본질적인 서비스에서 의료행위 외의 부가적인 의료서비스에 이르기까지 다양하고 포괄적인 서비스를 요구하는 추세라는 것을 반영 한다. Go[19] 등의 연구에서는 선호하는 치과 의료 기관의 종류로 원장 2 인 이상인 의원 $52.4 \%$, 병원 $28.9 \%$ 로 조사되어 이와 같은 추세를 뒷받침하는 결과라고 할 수 있다.

Chun과 Lee[20]의 연구에서는 의료진의 경력, 의료진의 전문의 수련여부, 치과의 명성, 거리 및 교통편리, 주차 편리, 내부 인테리어, 최신 기구의 사용, 치과 규모, 친절성, 진료비, 야간 및 공휴일 진료 여부, 진료 대시 시간 등의 요인에 대하여 연 구대상자의 $50 \%$ 이상이 중요하다고 응답하였는데, 치과 의료소비자들은 치과 의료기관 선택에 있어 다양한 판단 기준을 적용하는 것으로 보인다. 그렇 지만 지금까지의 연구들은 치과 병원과 의원을 구 분하여 그 선택 기준을 평가하지는 않았다.

이번 연구에서 전체 대상자 410 명 중 방문한 치 과의원과 치과병원의 종별을 인지하였다고 응답한 경우는 $68.8 \%$ 였으며, 그 중 치과의원을 정확하게 인지하고 방문한 경우는 125 명 중 92 명 $(73.6 \%)$, 치 과병원을 정확하게 인지하고 방문한 경우는 157 명 중 130 명 $(82.8 \%)$ 이었다. 이 결과에서 치과 환자의 $1 / 3$ 은 치과 의료기관의 종별에 관계없이 치과 의 료서비스를 이용하며, 치과 의료기관의 종별을 인 지하는 환자들 중에서는 치과병원 방문 환자들이 상대적으로 더 정확하게 인지하고 방문한다는 점 을 확인할 수 있었다.

치과의원과 치과병원의 선택 기준에 있어서는 뚜렷한 차이는 없었으며, 인력, 시설 및 장비, 서비 
스의 순으로 중요시 한다는 점은 동일하였다. 다 만, 시설 및 장비 부문에 대한 점수는 치과병원을 방문한 환자들이 치과의원을 방문한 환자들 보다 유의하게 높았는데, 이 점은 치과병원들이 시설 및 장비, 환경 등에 대하여 보다 적극적인 홍보 및 광 고를 하는 이유를 뒷받침하는 것일 뿐만 아니라, 진단과 치료에 있어 환자들의 첨단 의료장비에의 의존성과 인식수준이 치과병원을 명확하게 인식하 고 방문하게 한 것일 수도 있다. 향후 의료기술의 발달과 함께 첨단 의료장비에 대한 의존성은 더욱 높아질 것으로 예상되며 치과 의료소비자들의 관 심 또한 증가 할 것이기 때문에 이러한 점에 대해 관심과 추가적인 연구가 필요할 것으로 사료된다.

서비스 부문은 치과의원과 치과병원 환자들 사 이에 총점은 유의한 차이가 없었지만, 개별 항목 중 교통의 편리성은 치과병원 인지 환자들에 있어 서 중요한 선택 요인으로 작용하고 있다는 점을 알 수 있었다.

이 연구의 제한점으로는 치과환자들의 종별 인 지 여부에 대해 선행연구에서 실증 분석이 많이 이루어지지 않아 조사도구의 구조화 및 연구 모델 을 설정하는 데 어려움이 있었고, 아울러 설문 조 사 과정에서 다양한 치과 의료기관과 연령대를 포 함한 대상자들의 참여를 유도하지 못하였으며, 또 한 지역적으로 대구지역을 중심으로 이루어져 치 과의료 이용 전반으로 일반화하기에는 문제가 있 다는 제한점을 지닌다. 그렇지만, 치과 의료기관을 병원과 의원으로 구분하여 인지 여부 및 정확도를 평가하고, 각각의 선택 기준을 조사한 것은 기존 논문과 차별화되는 성과라고 할 수 있다.

결론적으로 치과환자들은 치과의원 및 치과병원 선택에 있어 모두 의료인력, 시설 및 장비, 서비스 부문의 순으로 중요하게 생각하였고, 치과병원 환 자들이 치과의원 환자들보다 종별을 더 정확하게 인지하고 방문하였다. 치과병원 환자들은 시설 및 장비 부문을 상대적으로 더 중요한 선택 기준으로
간주하였고, 서비스 부문 중 교통의 편리성이 또한 중요한 선택 기준이었다.

향후 이번 연구 결과를 토대로 보다 정확한 표 본 선정과 정교한 선택요인 개발을 통하여 치과의 료 이용자들의 치과 의료기관 선택에 관한 추가적 인 연구가 진행 될 수 있을 것이다.

\section{REFERENCES}

1. Ministry of Health and Welfare(2012), Ministry of Health and Welfare Year Book 2011, pp.131-155.

2. http://www.hira.or.kr/dummy.do?pgmid=HIRA A020045000000\&cmsurl $=/ \mathrm{cms} /$ information $/ 0$ 5/03/01/1210719_13603. html

3. Y.G. Kim, G.T. Jeong, Y.S. An, S.E. Lee, Y.H. Jang, B.L. Han(2003), The Influence of Dental Service Qualities on the Patient Satisfaction and Royalty in Dental Clinics and Hospitals, J. of Korea Society of Hospital Administration, Vol.8(3);49-71.

4. I.S. Khang(2001), A Study on the Dental Consumer's Dental Clinic Choice Criteria, Master Thesis, Graduate School of Industry \& Business Administration, Hanyang University, pp.51-58.

5. K.Y. Cho(2006), An Empirical Study on Choice Factors for Dental Clinics in Daejeon, Korea, Master Thesis, Graduate School of Business Administration, Woosong University, pp.1-88.

6. Y.H. Choi(2006), A Study on the Primary Factors in the Selection of Dental Medical Organizations, J. of Korea Society of Dental Hygiene, Vol.6(3);229-242.

7. G.S. Lee(2009), Study on Selection Factor in Choosing Dental Clinic, J. of Korean Academy of Dental Technology, Vol.31(2);15-22.

8. J. Kim, C.S. Park, E.J. Kang(2007), A study on 
Medical Consumers' Selection of Dental Clinic Institutions Depending on Their Lifestyle, J. of Korean Academy of Oral Health, Vol.31(4);568-580.

9. D.I. Sung(2007), A Study on Exert Influence on Satisfaction and Reuse Intention by Choice Factors for Dental Clinic, Master Thesis, Graduate School of Industry, Kumoh National Institute of Technology, pp.1-38.

10. E.K. Jung(2010), Choosing Patterns for Dental Clinic among Community People, J. of Dental Hygiene Science, Vol.10(5);323-327.

11. Y.Y. Yoon, S.H. Yu, Y.Y. Kim, H.J. Oh(2003), Attitudes on Medical Market Opening and Factors for Selecting a Foreign Hospital of Korean University Hospital Outpatients, J. of Korea Society of Hospital Administration, Vol.33(4);83-94.

12. K.E. Kim(2003), The Analysis on the Degree of Recognition and Satisfaction with Network Clinics, Master Thesis, Graduate School of Business Administration, Kyunghee University, pp.1-61.

13. S.I. Hwang, H.J. Lee, J.K. Kim, W.H. Cho, J.M. Kim, H.Y. Kang(2010), Hospital Attributes Considered by Patients with Spinal Diseases in Choosing Speciality or General Hospitals, J. of Korea Society of Hospital Administration, Vol.15(2);27-43.

14. K.W. Cho(2010), Hospital Selection Factors and Degree of Satisfaction of Aesthetic Plastic Surgery Patients, J. of Health Service Management, Vol.4(2);97-106.

15. H.H. Park(1998), A Study on Selection Factor in Choosing Dental Clinic, Focused on Seongnam City, Gyeonggi Province, Master Thesis, Graduate School of Public Administration, Hanyang University, pp.1-54.
16. H.J. Choi(2004), Information Searching Behavior and Factors Affecting Choosing Dental Institutions, Master Thesis, Graduate School of Public Health, Inje University, pp.1-37.

17. Y.N. Kim(1997), A Study on Selection Factor of Patient in Choosing Dental Clinic, Master Thesis, Graduate School of Public Administration, Dankook University, pp.1-55.

18. G.S. Lee, T.Y. Sohn(2012), Hospital Selection Factors and Patient Satisfaction of Refractive Surgery Patients, J. of Health Service Management, Vol.6(4);279-294.

19. E.K. Go, S.L. Lee, J.H. Choi(2011), Analysis of Selection Criteria for a Dental Clinic and Satisfaction, J. of The Korean Academy of Dental Hygiene, Vol.13(1);1-16.

20. J.A. Chun, K.Y. Lee(2010), Importance and Influence in Factors of Selecting Dental Clinics in Some Regions, J. of Korean Society of Dental Hygiene Science, Vol.10(1);45-54.

접수일자 2013년 2월 8일 심사일자 2013년 2월 18일 게재확정일자 2013년 3월 18일 